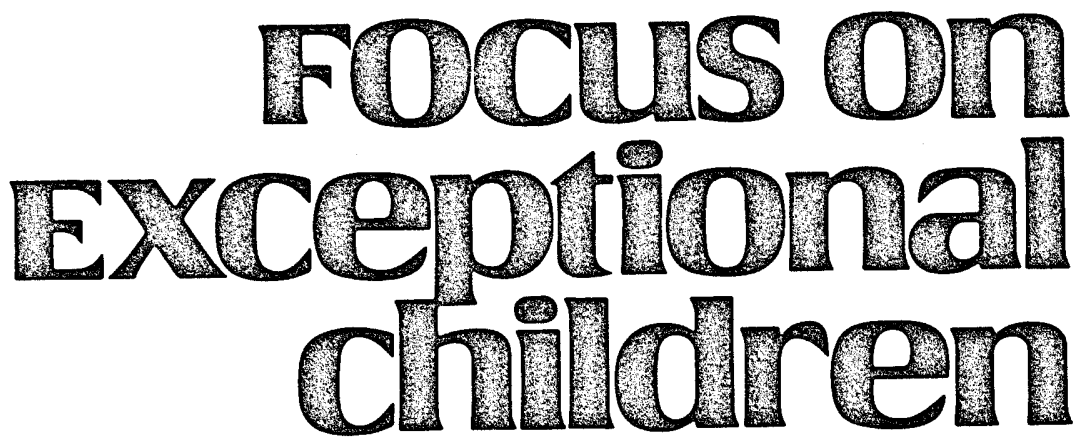

\title{
Attention Deficit Disorder: Issues and Questions
}

\author{
Janet W. Lerner and Sue R. Lerner
}

Attention deficit disorder (ADD) is one of the most common disorders of childhood, accounting for half of all child referrals to outpatient mental health clinics. With increasing frequency, physicians and psychologists are identifying the syndrome of ADD in children (DuPaul, Barkley, \& McMurray, 1991; Frick \& Lahey, 1991). Terminology in this field can be disconcerting because of the variety of terms, in addition to ADD, used to refer to this condition: attention-deficit hyperactivity disorder (ADHD), attention deficit disorder with hyperactivity (ADDH), and others. Following the suggestion of Henker and Whalen (1989) that these different terms represent a family of disorders and should be used interchangeably, ADD is used in this article to refer to the entire family of disorders.

We do not intend to cover every part of the complex phenomenon of ADD but, rather, to examine it from the educator's perspective. This article covers dimensions of $\mathrm{ADD}$ of value to educators, namely ADD and special education legislation, the history of ADD, associated conditions, assessment, treatment, and current issues.

Although the terminology, definition, and diagnostic criteria have varied over the past 50 years that the condition has been reported in the literature, individuals with ADD are usually characterized as having difficulty staying on task, focusing attention, and completing work. In addition, they often display symptoms of age-inappropriate hyperactive behavior, are easily distracted, racing from one idea or interest to another, or produce sloppy and carelessly done work. They impart the impression that they are not listening or have not heard what they have been told.

For parents, physicians, psychologists, educators, legislators, and for the children themselves, the issues and questions surrounding ADD are complex and controversial. Physicians and psychologists increasingly diagnose ADD in children, yet the precise nature of the disorder and its treatment remain enigmatic. Parents tend to accept with relief a physician's diagnosis of ADD for their child because it is a known diagnostic medical entity, but their relief is soon replaced by anxiety and frustration as physicians, psychologists, parents, and educators attempt to clarify the implications of the diagnosis and come up with the most reasonable and effective treatments (Frick \& Lahey, 1991; Shaywitz \& Shaywitz, 1991).

Janet W. Lerner is a Professor of Special Education at Northeastern Illinois University in Chicago. Sue Lerner earned her Ph.D. at the University of Texas and is currently on the staff of the DayGlow Family Treatment Program in Austin, Texas. 


\section{ADD AND SPECIAL EDUCATION LEGISLATION}

The two federal laws that are especially pertinent for children with ADD in the schools are (a) the Individuals with Disabilities Education Act (IDEA) and (b) Section 504 of the Rehabilitation Act.

\section{Individuals with Disabilities Education Act (IDEA)}

In October of 1990, Congress passed the Individuals with Disabilities Act (IDEA) (Public Law 101-476). This law is a reauthorization of Public Law 94-142, Education of the Handicapped Act (EHA), which has served the special education community for more than 12 years. In the reauthorization, the title of the law was changed to the Individuals with Disabilities Act (highlighting "individuals" instead of "children" and "disabilities" instead of "handicaps"). The most controversial debate surrounding IDEA was whether the law should or should not identify ADD as a separate disability. Advocates of identifying ADD as a separate category argue that ADD is an identifiable condition recognized by the med-

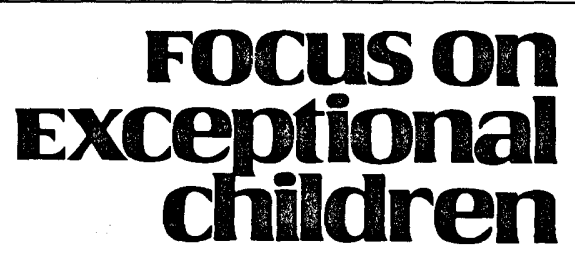

ISSN 0015-511X

FOCUS ON EXCEPTIONAL CHILDREN (USPS 203-360) is published monthly except June, July, and August as a service to teachers, special educators, curriculum specialists, administrators, and those concerned with the special education of exceptional children. This publication is annotated and indexed by the ERIC Clearinghouse on Handicapped and Gifted Children for publication in the monthly Current Index to Journals in Education (CIJE) and the quarterly index, Exceptional Children Education Resources (ECER). It is also available in microfilm from Xerox University Microfilms, Ann Arbor, MI. Subscription rates: Individual, \$27 per year; institutions, $\$ 36$ per year. Copyright (c) 1991, Love Publishing Company. All rights reserved. Reproduction in whole or part without written permission is prohibited. Printed in the United States of America. Second class postage is paid at Denver, Colorado. POSTMASTER: Send address changes to:

Love Publishing Company

Executive and Editorial Office

1777 South Bellaire Street

Denver, Colorado 80222

Telephone (303) 757-2579

Edward L. Meyen University of Kansas

Glenn A. Vergason Georgia State University

Richard J. Whelan

University of Kansas Medical Center

Stanley F. Love Publisher
Holly T. Rumpler Senior Editor ical field and that children with ADD are not adequately served (Barkley, 1990; Thomas, 1990). Opponents of identifying ADD as a separate category within the law argue that children with ADD can already be served under other disability categories, such as learning disabilities (LD), emotional disturbances (ED), or other health impaired (OHI), and therefore a separate category for ADD is unneeded (ED Issues/Questions on Attention Deficit Disorder, 1990; Council for Exceptional Children, 1991; Council for Learning Disabilities, 1991; Learning Disabilities Association, 1991).

\section{Recognition of ADD as a Disability under IDEA}

ADD was finally recognized as a disability under the Individuals with Disabilities Act (IDEA) on September 16, 1991 in a Policy Memorandum issued by the U.S. Department of Education. The Department of Education expressly recognized children with attention deficit disorder (ADD/ ADHD) as eligible for special education and related services under federal law when ADD impairs educational performance or learning. The policy memorandum stated that ADD does not need to be added as a separate disability category because children with ADD who require special education and related services can meet the eligibility criteria for services under existing categories of IDEA. If the primary disability is ADD, students are eligible under statutes and regulations of the category "Other Health Impaired" (Education of the Handicapped, 1991). For some children with ADD, the primary disability area for eligibility will be learning disabilities or emotional disturbances.

STATEMENT OF OWNERSHIP, MANAGEMENT AND CIRCULATION

Date of Filing: October 1, 1991

Title of Publication: FOCUS ON EXCEPTIONAL CHILDREN

Frequency of Issue: Monthly except June, July, and August

Location of Known Office of Publication: 1777 S. Bellaire St., Denver, CO 80222

Location of Headquarters of Publisher: 1777 S. Bellaire St., Denver, CO 80222

Name and Address of Publisher, Editor, and Managing Editor: Stanley F. Love, 1777 Bellaire St., Denver, CO 80222

Owner: Stanley F. Love

Extent and Nature of Circulation: Average No. Copies Each Issue During Preceding 12 Months

Single Issue Nearest
Filing Date

Total No. Copies Printed 3,238

Paid Circulation

Sales through Dealers, etc.

Mail Subscriptions

Total Paid Circulation

Free Distribution

Total Distribution

Office Use and Left Over

Total

0
2,334
2,334
350
2,684
554
3,238

3,300

0

2,129

2,129

372

2,501

799
3,300

I certify that the statements made by me above are correct and complete. 
Leading up to the recognition of ADD by the U.S. Department of Education were several critical events. Congress did not include ADD when IDEA was passed in October 1990, but opted to obtain more information on the current issues surrounding children with ADD. The Department of Education was directed to hold public hearings and seek public response to several questions dealing with Attention Deficit Disorder, including the degree to which children with ADD are currently excluded from special education services, unique characteristics of children with ADD, recommended criteria for the identification of children with ADD, and protection issues regarding misclassification of minority students (OSEP sends notice of inquiry summary, 1991). The specific questions for public hearings are listed in the accompanying box.

\section{ADD as a Separate Category: Pros and Cons}

The intense debate about establishing ADD as a separate category of disability in the federal legislation of IDEA underscores basic differences of opinion. Support for a separate category for ADD comes from certain parent groups (e.g.,
CH.A.D.D.: Children with Hyperactivity Attention Deficit Disorders) and some medical professionals (Barkley, 1990; Thomas, 1990). Opponents of this action include other parent groups (e.g., LDA: Learning Disabilities Association) and some special education entities (e.g., Council for Exceptional Children). In part, this difference is due to the sources of authority for these two groups. For medical professionals and psychologists, the Diagnostic and Statistical Manual of Mental Disorders (DSM), published by the American Psychiatric Association, is the basic source of nomenclature, definitions, and criteria. In contrast, special educators and school personnel are inclined to look at rulings from the IDEA legislation. In effect, two classification systems are competing (Schaughency \& Rothlind, 1991).

\section{Responses to the Public Inquiry}

The public inquiry on ADD generated more than 2,000 responses, which were summarized by the Department of Education's Office of Special Education Programs (OSEP) and sent to Congress on May 17, 1991. The responses revealed a diversity of opinion surrounding each question. For

\section{Questions About ADD for Public Inquiry Under IDEA}

\section{As directed in IDEA (PL 101-476), the Department of Education held public hearings on} 12 questions about ADD:

1. Are children with ADD now being excluded from special education programs?

2. To what extent are children with $A D D$ identified within the existing disability categories?

3. Do children with ADD have unique characteristics not reflected in the existing categories? If so, to what extent do these characteristics require separate evaluation criteria, special preparation for teachers and staff, and distinct education programs and services.

4. What education programs and/or services are school districts now providing to children diagnosed with $A D D$, either in special education or in general education programs?

5. How should attention deficit disorder be described for purposes of qualifying a child for special education services?

6. What criteria should be included in the definition to qualify children with ADD whose disability is as severe as those of other children eligible for special education?
7. What specific manifestations of ADD should be included in the definition?

8. Should the definition include factors producing inattentive behaviors that alone should not make a child eligible for special education under the definition of ADD?

9. Should the definition address the concurrence of ADD with other disabilities?

10. Should guidelines be provided to state and local education agencies on their obligation to evaluate a child thought to have ADD?

11. Who should be authorized to conduct such evaluations, and should they be conducted by more than one person?

12. What should be in the definition, and should any additional steps be taken to ensure that children from racial, ethnic, and linguistic minorities are not misclassified? 
example, the question on whether children with ADD are being excluded from special education services prompted the following diverse responses (OSEP sends notice, 1991):

- Parents described personal experiences in which their child was denied services on the basis of an ADD diagnosis.

口 Children with ADD were being served under an existing category (such as learning disabilities or emotional disturbances), and the ADD problem was not being addressed.

- Concern was expressed about the effect of a delay in identification and service delivery to children with $\mathrm{ADD}$, resulting in the development of secondary handicapping conditions over time.

- Students with ADD are being served currently and are not excluded from services.

- The regular education program should be able to effectively address the needs of students with ADD if the problems are not significant enough to qualify them for special education.

In responses to the question of who should be authorized to conduct an assessment of a child having or suspected of having ADD, the diverse opinions included: only a physician, only educators, a multidisciplinary approach including both medical and educational assessment.

In its summary report, OSEP made no recommendations to Congress on whether to include ADD as a separate category of disability under IDEA. In the OSEP report, the Director of Policy and Planning for OSEP, Patty Guard, said:

OSEP recognizes the consistent confusion regarding obligations to evaluate children with ADD and the circumstances under which children with ADD are eligible for services under Part B. OSEP will issue a joint memo with the Office of Civil Rights regarding these obligations to provide assessment of children suspected of having ADD. (p. 160)

With the September 16, 1991 Policy Memorandum issued by the U.S. Department of Education, ADD is officially recognized in IDEA under the category of "other health impaired" (OHI). This assures that children with ADD will be recognized and served under the law even if they do not meet the eligibility criteria for learning disabilities or emotional disturbances (Parker, 1990; Teeter, 1991).

\section{Section 504 of the Rehabilitation Act}

Accommodations for children with ADD in the schools can also be provided through another federal law, Section 504 of the Rehabilitation Act of 1973. Enforced by the Office of Civil Rights (OCR) of the U.S. Department of Education, this law is a civil rights act that protects the civil and constitutional rights of handicapped individuals. This law is sometimes called the "curb cut" law because it is the legal basis of the mandated curb cuts in streets that allow wheelchairs (as well as strollers, bicycles, and so on) to more easily go from street to sidewalk. Section 504 of the Rehabilitation Act (PL 93-112), first passed by Congress in 1973, was expanded in 1978 to cover schools. The law states:

\footnotetext{
No otherwise qualified handicapped individual ... shall, solely by reason of his/her handicap, be excluded from participation in, be denied the benefits of, or be subject to discrimination under any program or activity receiving federal financial assistance.
}

Section 504 covers a broader population of individuals with handicaps than the Individuals with Disabilities Education Act (Madsen, 1990). As related to the educational setting, students with handicaps may not be receiving services from special education teachers but still require assistance in school because of their handicapping condition. A child with ADD is a "qualified handicapped person" under Section 504 if (a) the child is between the ages of 3 and 21, and (b) the handicapping condition substantially limits the child's ability to learn or to otherwise benefit from his or her education program.

If a school district regards a student as handicapped or if the student has previously been in a special education program, he or she qualifies for accommodations under Section 504. Many students currently served under Section 504 have physical disabilities and are provided barrier-free environments. Students who have documented health problems such as attention deficit disorders, as well as students who have identified learning disabilities but do not qualify for services under a district's severe eligibility specifications, can meet criteria to be served under Section 504. These students require specific accommodations to benefit from the educational process.

School districts should be aware of their obligations under Section 504, develop procedures for administering to their special needs students, and provide school staff with the techniques necessary to accommodate them. Classroom teachers can provide accommodations through classroom 
modifications, curriculum adaptations, time management, and delivery of instruction. School administrators can provide for the needs of children with ADD without major changes in school procedure (Reeves, 1990; Teeter, 1991).

By implementing Section 504, students with learning disabilities are able to enroll in college and postsecondary schools in steadily increasing numbers (Vogel, 1987). A recent survey shows that many colleges and postsecondary schools provide Section 504 access services for students with learning disabilities (Bursuck, Rose, Cowen, \& Yahaya, 1989). Section 504 college services include taped textbooks, note takers, counseling, individualized education plans, and basic skills instruction in reading, math, and language.

\section{HISTORY OF ADD}

Tracing the history of ADD offers an explanation of the origins of the various terms used to describe this syndrome and an historical perspective of the evolving theories. In the past 50 years, as researchers and clinicians wrote about the condition, many theories and terms evolved, including (a) brain damage syndrome, (b) minimal brain dysfunction (MBD), (c) hyperkinetic reaction of childhood, (d) attention deficit disorder with hyperactivity (ADDH) and attention deficit disorder without hyperactivity $(\mathrm{ADD} / \mathrm{noH})$, and (e) attention-deficit hyperactivity disorder (ADHD) and undifferentiated attention-deficit disorder (U-ADD) (Cantwell \& Baker, 1991; Frick \& Lahey, 1991; Lahey \& Carlson, 1991; Shaywitz, 1987; Shaywitz \& Shaywitz, 1988; Silver, 1990; Silver \& Hagin, 1990). A brief historical overview of the diagnostic terminology used over the years is summarized in Table 1.

\section{Brain Damage Syndrome}

The first report in the medical literature was an article by Still (1902), who described children with what he termed "morbid defects in moral control." His descriptions were remarkably similar to diagnostic criteria used today. Other investigators of that era were also beginning to link this behavior to traumatic brain injury and other childhood central nervous system infections (Goldstein, 1936; Meyer, 1904).

In the 1930s and 1940s, work on a specific behavioral syndrome in children arising from brain damage led to influential publications by Werner and Strauss (1941) and Strauss and Lehtinen (1947). Surveying a population of mentally defective, institutionalized children and using case history information and a neurological examination, those researchers linked the learning problems and symptomatic behaviors of some of these children to brain damage. They hypothesized that the insult to the brain could occur before, during, or after birth. The behaviors of the brain-damaged children were described as hyperactive, distractible, impulsive, emotionally labile, and perserverative. The work of Strauss \& Lehtinen (1947) alerted many physicians and educators to an alternative diagnosis for children who previously had been given other labels and to parents who had been blamed for the child's behavior.

\section{Minimal Brain Dysfunction (MBD)}

By the 1950s the medical literature reported that verifying brain damage in children with learning and behavioral problems was difficult and that these children looked normal. To differentiate this condition from true or gross brain damage, scholars suggested the term "minimal brain damage," a designation indicating that the brain damage was slight (Cantwell \& Baker, 1991; Laufer \& Denhoff, 1957; Shaywitz \& Shaywitz, 1991; Silver, 1990).

An elaboration of this concept, suggested by Clements and Peters (1962), was "minimal brain dysfunction," a term implying that these individuals did not have brain damage but, rather, difficulty with the way the brain functioned (Silver, 1990). In 1966, a report sponsored by the National Institute of Health (NIH) recommended that the term "minimal brain damage" be discarded and replaced by "minimal brain dysfunction" (MBD) (Clements, 1966). The definition of MBD was:

\begin{abstract}
Children of near-average, average, or above-average general intelligence with certain learning or behavioral disabilities ranging from mild to severe, which are associated with deviations of function of the central nervous system. These deviations may manifest themselves by various combinations of impairment in perception, conceptualization, language, memory, and control of attention, impulse, or motor function. (p. 9)
\end{abstract}

The concept of MBD was appealing to psychiatrists, neurologists, and psychologists because it allowed them to note neurological deviations of a subtle nature. The symptoms of MBD included specific learning deficits, hyperkinesis, impulsivity, and short attention span, and the diagnosis included evidence of "equivocal" neurological signs and an electroencephalogram (EEG) that is borderline or abnormal.

\section{Hyperkinetic Reaction of Childhood}

The concept of MBD proved to be controversial because it was not operational and lacked sufficient guidelines for 
TABLE 1

Historical Overview of Attention Deficit Disorder

\begin{tabular}{|c|c|c|c|}
\hline Date & Diagnostic Terminology & Source & Characteristics \\
\hline $\begin{array}{l}1941, \\
1947\end{array}$ & Brain damage syndrome & $\begin{array}{l}\text { Werner \& } \\
\text { Strauss }\end{array}$ & $\begin{array}{l}\text { Hyperactivity, distractibility, impulsivity, emotionality } \\
\text { unstable perserveration. }\end{array}$ \\
\hline 1962 & $\begin{array}{l}\text { Minimal brain dysfunction } \\
\text { (MBD) }\end{array}$ & $\begin{array}{l}\text { Clements \& } \\
\text { Peters }\end{array}$ & $\begin{array}{l}\text { Soft neurological indicators, specific learning deficits, } \\
\text { hyperkinesis, impulsivity, short attention span. }\end{array}$ \\
\hline 1968 & $\begin{array}{l}\text { Hyperkinetic reaction } \\
\text { of childhood }\end{array}$ & DSM II & Hyperactivity \\
\hline \multirow[t]{4}{*}{1980} & \multirow{3}{*}{$\begin{array}{l}\text { Attention deficit disorder } \\
\text { with hyperactivity (ADDH) }\end{array}$} & DSM III & (a) Inattention, impulsivity, motor hyperactivity \\
\hline & & & (b) Onset before age 7 \\
\hline & & & (c) Duration of at least 6 months \\
\hline & $\begin{array}{l}\text { Attention deficit disorder } \\
\text { without hyperactivity }(\mathrm{ADD} / \mathrm{noH})\end{array}$ & & Inattention, disorganization, difficulty completing tasks \\
\hline \multirow[t]{2}{*}{1987} & $\begin{array}{l}\text { Attention-deficit } \\
\text { hyperactivity disorder (ADHD) }\end{array}$ & DSM III-R & Any 8 of a set of 14 symptoms \\
\hline & $\begin{array}{l}\text { Undifferentiated attention } \\
\text { deficit disorder (U-ADD) }\end{array}$ & & Developmentally inappropriate and marked inattention \\
\hline 1991 & Attention deficit disorder (ADD) & $\begin{array}{l}\text { Policy } \\
\text { Memorandum, } \\
\text { U.S. Department } \\
\text { of Education }\end{array}$ & IDEA, Part B-Other Health Impaired \\
\hline
\end{tabular}

In process

DSM IV

Sources: Diagnostic and Statistical Manual of Mental Disorders (2nd ed.; 3rd ed.; 3rd ed., rev.; 4th ed.), 1968; 1980; 1987; and in process, Washington, DC: American Psychiatric Association. "Minimal Brain Dysfunction in the School-Aged Child" by S. D. Clements and J. E. Peters, 1962, Archives of General Psychiatry, 6, pp. 185-187. Psychopathology and Education in Brain-Injured Children by A. S. Strauss and L. E. Lehtinen, 1947, New York: Grune \& Stratton. "Pathology of the Figure-Background Relation in the Child" by H. Werner and A. S. Strauss, 1941, Journal of Abnormal \& Social Psychology, 36, p. 234-248. U.S. Department of Education, Policy Memorandum, September 16, 1991.

diagnosis. What was needed was a rigorous set of diagnostic criteria to identify the disorder. In 1968 the beginnings of a set of diagnostic criteria appeared in the second edition of the Diagnostic and Statistical Manual of Mental Disorders (DSM II) (American Psychiatric Association, 1968). The term "hyperkinetic reaction of childhood" was used to describe the hyperactive child. The disorder was characterized by overactivity, restlessness, distractibility, and short attention span (Silver, 1990).

\section{Attention Deficit Disorder: ADDH and ADD/noH}

The third edition of the Diagnostic and Statistical Manual of Mental Disorders (DSM III) (American Psychiatric Asso- ciation, 1980) is considered a significant advance in the validity of diagnosis of attention deficit disorder (Cantwell \& Baker, 1991; Shaywitz \& Shaywitz, 1988). DSM III shifted the focus to attentional problems rather than activity problems, and it established the term "attentional deficit disorder." The role of attention in learning and within the larger cognitive system is complex. Attention impacts the rest of the system by what information it allows in at the sensory level, by how information is managed in short-term working memory, how information is encoded into long-term memory, and how information is retrieved from long-term memory (CherkesJulkowski, Stolzengerg, \& Segal, 1991; Torgesen, Kistner, \& Morgan, 1987). 
In DSM III, two types of ADD were noted: (a) ADD with hyperactivity (ADDH) and (b) ADD without hyperactivity $(\mathrm{ADD} / \mathrm{noH})$. To establish the diagnosis of ADDH, the child had to show evidence of three criteria: (a) inattention, (b) impulsivity, and (c) motor hyperactivity. DSM III specified behaviors for each of the three criteria. The diagnosis of $\mathrm{ADD} / \mathrm{noH}$ was for children who exhibited attentional deficits and impulsivity but no hyperactivity. Other diagnostic criteria for both ADDH and ADD/noH specified the age of onset as prior to 7 years and a duration of at least 6 months.

\section{Attention Deficit Hyperactivity Disorder (ADHD)}

In 1987, publication of the Diagnostic and Statistical Manual of Mental Disorders-Revised (DSM III-R) (American Psychiatric Association, 1987) revealed further modifications. The term "attention-deficit hyperactivity disorder" (ADHD) was used to reflect recent research showing that distractibility was a primary issue but hyperactivity was also an important factor in this disorder (Silver, 1990). For a diagnosis of ADHD, DSM III-R allowed any 8 symptoms to be selected from a set of a possible 14. Also, it kept the criteria for age of onset as prior to 7 years and duration of the behavior for at least 6 months. The diagnostic criteria for ADHD specified in DSM III-R are shown on page 8.

The type of ADD without hyperactivity (noted in DSM III) was relegated to minor status in DSM III-R (Barkley, DuPaul, \& McMurray, 1991). Instead, DSM III-R describes a category called "undifferentiated attention-deficit disorders (U-ADD)," which roughly corresponds to children identified as ADD/noH in DSM III. Epstein, Shaywitz, Shaywitz, and Woolston (1991) believe these children are an underidentified, underserved group at significant risk for long-term academic, social, and emotional difficulties. Children with $\mathrm{ADD} / \mathrm{noH}$ are far less visible and less likely to come to the attention of parents, educators, or other professionals; but, at the same time, they may be at much greater risk for school failure and social failure than children who have ADD with hyperactivity (Shaywitz, 1987).

Recent studies show that children with attention deficit disorders without hyperactivity represent a distinct category of ADD (Barkley et al., 1991; Lahey \& Carlson, 1991; Schaughency \& Rothlind, 1991). Compared to children having hyperactivity with attention deficit disorders, these children exhibit less serious conduct problems, are less impulsive, are more likely to be characterized as sluggish and drowsy, are less rejected by peers but more socially withdrawn, and are more likely to show depressed moods and symptoms of anxiety disorder. Many researchers recom- mend that ADD without hyperactivity represents a clinically meaningful entity and should be included as a distinct diagnostic category in DSM IV, which is currently in development (Epstein et al., 1991).

\section{ASSOCIATED CONDITIONS}

The classification of children with ADD is intrinsically related to classification efforts for other learning and behavior disorders (Fletcher, Morris \& Francis, 1991). To be eligible for services under IDEA, a child must be classified under one of three existing disabilities: (a) specific learning disabilities (LD), (b) seriously emotionally disturbed (ED), or (c) other health impaired (OHI). August and Garfinkel (1989) designated two subtypes of ADHD: "behavioral" and "cognitive." The cognitive subtype is associated with LD and is characterized by severe academic underachievement and neuropsychological skill deficits having to do with encoding the retrieval of linguistic information. The behavioral subtype is characterized by conduct disorders and aggressive behavior, in addition to inattention, impulsivity, and overactivity.

\section{Learning Disabilities and ADD}

Accumulating evidence indicates a significant overlap between ADD and learning disabilities (LD). ADD is not a learning disability, but it is a disorder associated with learning disabilities (Silver, 1990). The relationship between LD and ADD is still unclear, with varying co-occurrence estimates (Shaywitz, 1987). A major problem is the inconsistent criteria used to diagnose both ADD and LD. Each is presumed to stem from a neurological disorder. With $L D$, it impacts the basic psychological processes involved in academic functioning. With ADD, it is manifested in hyperactivity (controlling motor activity level), distractibility (determining which external stimuli are relevant or not relevant), and impulsivity (reflecting before acting) (Shaywitz \& Shaywitz, 1988; Silver, 1990). One study shows that children with untreated ADD (children who were not prescribed medication) were difficult to differentiate from those who had forms of learning disabilities (Cherkes-Julkowski \& Stolzengerg, 1991).

Current estimates of co-occurrence of ADD and LD vary widely. A substantial proportion of ADD children (23-30\%) have difficulties achieving up to a level predicted by their age and general intelligence (Epstein et al., 1991; Frick \& Lahey, 1991; Shaywitz \& Shaywitz, 1991). Moreover, between 15 and $20 \%$ of children and adolescents with learning disabilities will have ADD (Silver, 1990). Studies also show 


\section{Diagnostic Criteria for Attention-Deficit Hyperactivity Disorder (DSM III-R)}

Note: Consider a criterion met only if the behavior is considerably more frequent than that of most people of the same mental age.

A. A disturbance of at least six months during which at least eight of the following are present:

1. often fidgets with hands or feet or squirms in seat (in adolescents may be limited to subjective feelings of restlessness)

2. has difficulty remaining seated when required to do so

3. is easily distracted by extraneous stimuli

4. has difficulty awaiting turn in games or group situations

5. often blurts out answers to questions before they have been completed

6. has difficulty following through on instructions from others (not due to oppositional behavior or failure of comprehension); e.g., fails to finish chores

7. has difficulty sustaining attention in tasks or play activities

8. often shifts from one uncompleted activity to another
9. has difficulty playing quietly

10. often talks excessively

11. often interrupts or intrudes on others; e.g., butts into other children's games

12. often does not seem to listen to what is being said to him or her

13. often loses things necessary for tasks or activities at school or at home (e.g., toys, pencils, books, assignments)

14. often engages in physically dangerous activities without considering possible consequences (not for the purpose of thrill-seeking); e.g., runs into street without looking

Note: The above items are listed in descending order of discriminating power based on data from a national field trial of the DSM III-R criteria for disruptive behavior disorders.

B. Onset before the age of 7

C. Does not meet the criteria for a pervasive developmental disorder

\section{Criteria for Severity of Attention-Deficit Hyperactivity Disorder (pp. 52-53):}

Mild: Few, if any, symptoms in excess of those required to make the diagnosis and only minimal or no impairment in school and social functioning

Moderate: Symptoms or functional impairment intermediate between "mild" and "severe"
Severe: Many symptoms in excess of those required to make the diagnosis and significant and pervasive impairment in functioning at home and school with age peers

The Diagnostic and Statistical Manual III-R (1987) also defines undifferentiated attention-deficit disorder as (p. 95):

A residual category for disturbances in which the predominant feature is the persistence of developmentally inappropriate and marked inattention that is not a symptom of another disorder, such as mental retardation or attention-deficit hyperactivity disorder, or a disorganized and chaotic environment. Some of the disturbances that in DSM-III would have been categorized as attention deficit disorder without hyperactivity would be included in this category. Research is necessary to determine if this is a valid diagnostic category and, if so, how it should be defined.

Source: From Diagnostic and Statistical Manual of Mental Disorders (3rd ed., rev.), 1987, Washington, DC: American Psychiatric Association. Reprinted by permission. 
that $33 \%$ of LD students exhibit hyperactivity and that $11 \%$ of ADD children have significant problems in reading or arithmetic (Shaywitz \& Shaywitz, 1988). The question of co-occurrence of ADD and LD and their mechanisms of interaction is important and merits further study.

\section{Behavior/Emotional Disorders and ADD}

The most significant problems associated with ADHD are aggressive and antisocial behaviors. Between 30 and $90 \%$ of children diagnosed with ADHD have significant conduct problems (Frick \& Lahey, 1991). Many children with ADHD are referred by schools or parents for evaluation and treatment because of behavioral problems. These difficulties are often related to inattentiveness, overactivity, and impulsivity. The children require adult attention at home and school for behaviors such as noncompliance, excessive and inappropriate verbalizations, not completing or attending to tasks, and disturbing other children. In addition, their intrusiveness and bossiness, coupled at times with aggressive behavior and poor social skills, lead to unsatisfactory peer relations and often to outright peer rejection (Abikoff, 1991).

Under current federal law (IDEA), children with ADD may be classified and receive services under the disability category of seriously emotionally disturbed. The term used in DSM III-R and preferred by many medical specialists and psychologists is conduct disorders.

In the public inquiry on ADD, more than 800 people responded to the question concerning the extent to which children with ADD are being identified within existing disability categories (OSEP, 1991). Many commenters expressed the view that the existing disability categories are not sufficient to appropriately identify children with ADD. Parents often noted their reservations about identifying their children as emotionally handicapped. The responses reveal that parents do not like the term "behavior disorders." They are embarrassed by it and feel their child does not need the stigma that they perceive is attached. Many parents refuse placement when the classification of "seriously emotionally disturbed" is the only alternative. Teachers often report that the classroom behaviors of ADD children are considerably different from those of other ED children.

\section{Other Health Impaired (OHI)}

The disability category of other health impaired (OHI) offers the third option under IDEA for identifying and providing services to children with ADD (Teeter, 1991; Thomas, 1990). Although this is now an option, few children with ADD are presently identified under this category, and only a small percentage of the total school population (about .12\%) is served under OHI (U.S. Department of Education, 1991, p. A-49). Of course, as more ADD children are identified under OHI, this percentage will increase substantially.

Children with health impairments require ongoing medical attention, stemming from a wide variety of conditions. Traditionally, the conditions under OHI include asthma, cystic fibrosis, heart defects, cancer, diabetes, and hemophilia. These conditions may not interfere with the child' ability to participate in regular classroom activities and may not require curricular adaptations, but they can require medication or special medical treatment. Teachers working with $\mathrm{OHI}$ children should know about medical procedures needed at school, limitations on activities, and emergency procedures that may be necessary if problems arise (Kirk \& Gallagher, 1989). How children with ADD will be identified and served under the disability category of $\mathrm{OHI}$ will require further study and investigation.

\section{ASSESSMENT}

$\mathrm{ADD}$ is a behavioral diagnosis, requiring multimethod behavioral assessment. The goal of assessment is to make appropriate administrative decisions about eligibility for services and to facilitate linkages with other professionals and agencies, as appropriate (Schaughency \& Rothlind, 1991). Schools are in a unique position to contribute to the identification and assessment of children with ADD. Because children spend 6 hours a day, 5 days a week, and 40 weeks per year in school, the school setting is important. Children can be observed doing a variety of academic and social tasks across a number of settings, and observed by multiple peers and adults. The child's problem is often first noted by the teacher after the child enters school. Moreover, studies show that teachers are able to distinguish between children with and without symptoms of ADD. Thus, a wealth of clinical information is available through the schools (Atkins \& Pelham, 1991).

In school-based assessment of ADD, multiple measures should be used, including teacher rating scales, direct observations in classrooms and playgrounds, peer rating and sociometric measures, and academic performance (Atkins \& Pelham, 1991; Schaughency \& Rothlind, 1991).

\section{Teacher Rating Scales}

Because teacher ratings are the most easily obtained measure of the child's classroom behavior, they are the predominant method of collecting information. Some teacher rating scales are: 
a Conners Teacher Rating Scale (CTRS) (Conners, 1969). The CTRS is one of the most frequently used scales designed to assess teacher perceptions of hyperactivity and related problems. The CTRS contains 39 items, which rate five factors: daydreaming-inattentive, hyperactive, conduct problems, anxious-fearful, and socialcooperative.

- Hyperkinesis Index, Abbreviated or Short-Form (Conners, 1973). The Hyperkinesis Index consists of 10 items from the original CTRS. A score of 15 of a possible 30 is considered the cutoff for classifying a child as hyperactive (Werry et al., 1975).

- IOWA-Conners Rating Scale (Loney \& Milich, 1982). The IOWA-Conners Rating Scale consists of 10 items from the original 39 items of the CTRS. Five of the items are designed to measure inattention/overactivity, and the five remaining items measure aggression. Empirical evaluations have demonstrated considerable evidence for the IOWA-Conner's validity as a measure of ADHD (Atkins \& Milich, 1988).

\section{Direct Observations}

Direct observation of classroom and playground behavior has been an important aspect of school-based assessment of ADHD. In direct observation, trained observers watch in a classroom situation and note specific targeted behaviors, through time-sampling methods. Direct observations are less subjective than ratings because they provide clearly defined measures that minimize inference on the observers' part. Research shows that direct observation methods do document differences between children with and without hyperactivity on objective measures of classroom behaviors (Abikoff, Gittelman, \& Klein, 1980). Although direct observation methods are especially useful for research purposes, the method is costly for general assessment purposes.

\section{Peer Ratings and Sociometrics}

Children with ADD often have problems in social relations. Two common measures of peer acceptance are peer nominations and peer ratings. In peer nominations, children are asked to nominate a predetermined number of classmates (usually three) as those whom they most like and those whom they least like. In peer ratings, classmates rate specific behaviors. On both of these measures, children with ADD are rated as less popular and more disliked. Children with ADD who are also aggressive generate the most negative peer evaluations (Pelham \& Milich, 1984).

\section{Measures of Academic Performance}

Measures of academic achievement and performance also add to the assessment picture. For example, if the item related to attention is the behavior "fails to finish things he starts," an assessment of the various classroom tasks the child is required to do adds significant diagnostic information (Atkins \& Pelham, 1991).

\section{TREATMENT}

Most experts recommend a multimodal treatment for ADD. It should include combined therapies of medication, education, family counseling, and parent training.

\section{Medical Treatment}

Psychopharmalogical therapy, or the use of medication, has proven effective in treating ADD. Psychostimulant medications (central nervous system stimulant drugs) are given most frequently. The stimulant medications have a higher probability of success and have been studied most extensively (Anastopoulos, DuPaul, \& Barkley, 1991; DuPaul, Barkley, \& McMurray, 1991; Swanson, Cantwell, Lerner, McBurnett, \& Hanna, 1991). The psychostimulant medications include Ritalin, Dexedrine, and Cylert (See Table 2). About $60-90 \%$ of the children with ADD are prescribed a regimen of stimulant therapy at some point during their school-age years, most often Ritalin (Landau \& Moore, 1991). By some estimates, stimulant medications improve attention and reduce overactivity and even aggression in $70-80 \%$ of ADD children (Silver, 1990; Parker, 1988). With less frequency, antidepressant medications are used with a favorable response. These include Trofanil (imipramine) and Desipramine (norpramine) (Pliszke, 1987; Shaywitz \& Shaywitz, 1988).

Psychostimulant medications increase the arousal or alertness of the central nervous system. The way in which stimulant medication alters deficits of ADD children in the domains of inattention, impulsivity, and overactivity is complex and still under study.

Research reviews on the effectiveness of stimulant medication consistently demonstrate that it improves children's classroom manageability and attention (Barkley, 1977; DuPaul et al., 1991; Gittelman-Klein \& Klein, 1987). Recent studies suggest that medication also increases academic productivity (Swanson, Cantwell, Lerner, McBurnett, \& Hanna, 1991). More than $70 \%$ of children with ADD taking these medications show behavioral, academic, and attention improvements, according to parent/teacher ratings, labora- 


\section{TABLE 2}

Psychostimulant Medications

\begin{tabular}{lll}
\hline $\begin{array}{l}\text { Brand } \\
\text { Name }^{\star}\end{array}$ & $\begin{array}{l}\text { Dosage } \\
\text { Regimen }\end{array}$ & $\begin{array}{l}\text { Dose } \\
\text { Range }\end{array}$ \\
\hline $\begin{array}{l}\text { Ritalin } \\
\text { (methylphenidate) }\end{array}$ & Twice daily ${ }^{\star \star}$ & $2.5 \mathrm{mg}$ to $25 \mathrm{mg}$ \\
$\begin{array}{l}\text { Dexedrine } \\
\text { (d-amphetamine) }\end{array}$ & Once daily & $2.5 \mathrm{mg}$ to $20 \mathrm{mg}$ \\
$\begin{array}{l}\text { Cylert } \\
\text { (pemoline) }\end{array}$ & Once daily & $18.75 \mathrm{mg}$ to $112.5 \mathrm{mg}$ \\
\hline
\end{tabular}

*Generic name in parenthesis.

${ }^{*}$ Slow-release dosage can be given once daily.

Source: From "Therapeutic Effects of Medication on ADHD: Implications for School Psychologists" by G. DuPaul, R. Barkley, and M. McMurray, 1991, School Psychology Review, 20, pp. 203-219.

tory task performance, and direct observations (Anastopoulos et al., 1991).

Cherkes-Julkowski and Stolzengerg (1991) compared 21 ADD children who received medication with 20 ADD children who did not receive medication and found that the medicated ADD group performed better in certain areas, particularly as related to working memory. But their data suggest the need for intervention beyond medication alone for children with ADD.

Current research focuses on differences between the responses of ADD children with hyperactivity (ADHD) and $\mathrm{ADD}$ children without hyperactivity $(\mathrm{ADD} / \mathrm{noH})$. One study of treatment responses to Ritalin (methylphenidate), conducted by Barkley et al. (1991), indicates that ADHD children respond differently to the medication than ADD/noH children. This study compared the responses of 23 ADHD children and $17 \mathrm{ADD} / \mathrm{noH}$ children to various dosages of $\mathrm{Ri}-$ talin (methylphenidate). The majority of the ADHD children responded positively, primarily to the moderate to high doses of methylphenidate, whereas the ADD/noH children had minimal or no response or did best on the low dose of medication. The researchers concluded that the $\mathrm{ADD} / \mathrm{noH}$ children may have a qualitatively different impairment in attention than ADHD children.

Diminished self-esteem is commonly associated with attention deficit disorder. Kelly et al. (1991) conducted a study of the changes in self-esteem of 21 ADD children, ages 8 to 12. Their research showed that initial self-esteem was low in $30 \%$ of the subjects, intermediate in $55 \%$, and high in $15 \%$. The children were assessed after a short-term course of treat- ment of Ritalin (methylphenidate) or a placebo, in a doubleblind crossover fashion. No significant changes in self-esteem were noted after the one-month course of treatment, but at long-term follow-up (averaging 16 months), self-esteem improved significantly. Long-term treatment consisted of multimodal management, including medical management, supportive counseling, and referral for psychosocial and educational assistance.

The most frequently reported side effects of stimulant medications given to children with ADD are insomnia or sleep disturbances, and decreased appetite, but these are temporary. In addition, a slowing in height growth was noted in some studies when the child received high doses over a long duration. Other studies show that when medication is reduced or is omitted for holiday periods, growth catches up. Of more concern is the onset of Tourette's syndrome or tics in some patients. Physicians, teachers, and parents should be alert to symptoms of tics so that medication can be eliminated or changed if this symptom appears (Silver \& Hagin, 1990).

\section{Educational Treatment}

Educational treatment for ADD is part of a total multimodal treatment approach. ADD is treatable through specialized, behaviorally based interventions in the medical setting, in conjunction with medication. Educational procedures include those used in special education for children with learning disabilities and behavioral disorders, modifications in the child's environment and assigned tasks, behavioral management methods, and cognitive training (Abramowitz \& O'Leary, 1991; McBurnett \& Pfiffner, 1991; Newby \& Fischer, 1991; Pfiffner \& Barkley, 1990).

\section{Importance of the Teacher's Understanding of $A D D$}

In addition to acquiring knowledge about ADD and its associated behaviors, teachers should recognize their own reactions to a child with ADD. Because of their impulsiveness, loud presence in the classroom, and persistence of their questions, comments, and demands, ADD children try teachers' patience and tend to become unpopular members of the classroom group. Teachers have to understand that much of this behavior is not intentional, not part of a ploy to defy educational authority. ADD children's activity level, annoying as it is to people around the youngster, is not always under voluntary control (Silver \& Hagin, 1990).

\section{Special Education Instruction}

If the child is eligible for special education, educational intervention is likely to follow the methods used in that cat- 
egory of disability. If the child is identified as having a learning disability, many of the procedures and methods are similar to those for treating a learning disability. If the child is identified as having a conduct disorder, the methods likely are those applied to children with an emotional disturbance. If children are identified in the category of other health impaired $(\mathrm{OHI})$, educational management has not yet been clearly established (Goldstein \& Goldstein, 1990; Parker, 1988; Silver, 1990). If a child is not identified for special education, accommodations can be made within the regular classroom, in the form of classroom modifications, curriculum adaptations, time management, and delivery of instruction.

Behavioral Intervention Strategies. One behavioral approach for children with ADD entails modifying the environment and the task. Several research studies have explored the effect of variables in the classroom setting and environment on the attention and hyperactivity of children with ADD. A summary of the finding of this research (Abramowitz \& O'Leary, 1991), shows that children with ADD are distracted by classroom noise, by tasks that are too difficult, and by tasks that are paced by others (as opposed to self-paced tasks). Attention is facilitated through greater task structure and increasing stimulation by adding color, shape, and texture. The research also shows that children attend better when class size is small; and their attention is higher in the resource room than in the regular classroom and during direct instruction (rather than seatwork).

Another approach, behavioral management, uses contingency management strategies, which apply consequences contingent on specific child behaviors. This approach has generated much research on children with ADD. Abramowitz and O'Leary (1991) review several different contingency management strategies with children who have ADD: contingent teacher attention, classroom token economies, home-school contingencies, peer-mediated interventions, time-out contingencies, and reductive procedures based on reinforcement.

- Contingent teacher attention calls for frequent verbal feedback (positive and negative) and nonverbal feedback (nods, frowns, smiles, and pats of approval). A combination of praising appropriate behavior while ignoring inappropriate behavior can successfully reduce classroom disruptiveness.

- Classroom token economies involve awarding or removing tokens or points to children contingent upon specific desirable or undesirable behaviors, which moti- vates youngsters and improves on-task behavior and academic achievement.

- Home-school contingencies combine the efforts of school and parents to improve children's classroom behavior. Teachers complete a brief daily checklist of three to five items, indicating whether the child met the goals for that day. The checklist is sent home, signed by parents, and returned. Parents provide appropriate consequences at home by applying contingencies that have been developed in advance. The advantage of this strategy is that it encompasses two environments, the school and the home.

- Peer-mediated intervention draws upon classmates of the ADD child as contingency managers. Peers are trained to praise appropriate behavior and ignore inappropriate behavior. Enlisting peer cooperation has proven to be efficient and successful in modifying the behavior of a target child (Abramowitz \& O'Leary, 1991).

- Time-out from positive reinforcement is a method of mild punishment in which the child is removed from the instructional setting for a brief period. Although it is well documented as a powerful and effective method of contingency management, time-out is controversial and can be misused. Abramowitz and O'Leary (1991) recommend that it be reserved for only the most disruptive classroom behaviors and administered only by highly trained staff.

- Reductive procedures based on reinforcement involve the use of reinforcers to reduce rates of inappropriate behavior. These techniques employ various schedules, timings, and rates of providing reinforcement. Abramowitz and O'Leary (1991) believe that the methods can be effective with children with ADD, particularly when they have associated conduct disorders.

Cognitive Training. Over the past 10 years, cognitive training has emerged as a major instructional procedure to teach children to act as their own behavior change agents. Two categories of behavior are targeted through cognitivebehavioral instruction: (a) teaching students self-monitoring and self-reinforcement strategies (Kendall \& Braswell, 1985; Meichenbaum, 1977; Meichenbaum \& Goodman, 1971); and (b) teaching students self-instructional and problem-solving cognitive skills (Abikoff, 1991; Deshler \& Schumaker, 1986). The strategy intervention model (SIM) has been researched extensively to help students with learn- 
ing disabilities (Deshler \& Schumaker, 1986). Its goal is to help students learn the strategies that effective learners use to control their own behavior and learning. These strategies include self-instructional training, cognitive modeling, selfmonitoring, self-reinforcement, and cognitive and interpersonal problem solving (Harris \& Pressley, 1991).

The central goal of cognitive training for children with ADD is the development of self-control skills and reflective problem-solving strategies, both of which are presumed to be deficient in children with ADD. These deficiencies are thought to account for difficulties in regulating attentive, impulsive, and interpersonal behaviors (Abikoff, 1991). The method is also referred to as cognitive behavior modification because students learn to control and modify their own behavior through self-behavior modification techniques (Meichenbaum, 1977), and learning strategies because students acquire methods that help them learn how to control their learning behavior (Deshler \& Schumaker, 1986).

Among the models of cognitive training, the learning strategies model developed at the University of Kansas Institute on Learning Disabilities offers a structure that has gained wide popularity (Ellis, Deshler, Lenz, Clark, \& Schumaker, 1991). This model has eight steps, as presented in Table 3.

Cognitive training methods used on children with learning disabilities and low-achieving children are effective in teaching academic skills (Ellis et al., 1991). Only a few studies, however, have targeted improving the cognitive behavior of ADD children. Some studies suggest that cognitive training for ADD children may be a useful adjunct to medical treatment or may be helpful when children are tapered off medication (Shaywitz \& Shaywitz, 1988).

\section{Family Counseling and Parent Training}

The ADD child and the family may benefit from family counseling to help repair injured self-esteem, overcome feelings of demoralization or depression, or learn more effective behavior approaches. Family problems can relate to the parents' handling of the child or adolescent, to the stress created within the family, or to problems with siblings (Parker, 1988). Parent training is often recommended as a treatment for children with ADD (Newby \& Fischer, 1991).

Being a parent is not easy, and having a child with a disability is even more difficult. When the disability is invisible, as in ADD, it creates even more stress for the parent. Parents may have difficulty accepting the reality that their child has a disability. A parent may show evidence of $d e-$ nial, refusing to accept the existence of the problem. As par-

\section{TABLE 3 Cognitive Training: Steps of the Learning Strategies Model}

\section{Step 1: Give pretest and obtain commitments} Assess student's present level of work.

Step 2: Describe the procedure

Give student the rationale for the procedure.

Step 3: Model the procedure

Demonstrate the procedure by talking aloud the thought process.

Step 4: Engage student in verbal rehearsal Have student go through the procedure by talking aloud

Step 5: Introduce controlled practice and feedback Have student practice the procedure in controlled, easy situation.

Step 6: Give grade-appropriate practice and feedback Have student practice the procedure in more difficult situation.

Step 7: Administer posttest and obtain commitment to generalize

Test student on learning.

\section{Step 8: Promote generalization}

Help student become aware of other situations and strategies for using the learning strategy.

Source: From "An Instructional Model for Teaching Learning Strategies" by E.S. Ellis, D.D. Deshler, B.K. Lenz, J.B. Schumaker, and F.L. Clark, 1991, Focus on Exceptional Children, 23(6), p. 11.

ents continue to struggle with the problem, they may become angry or feel guilty. The anger can be directed toward teachers and others; the guilt may lead to self-critical behavior or the need to do more for the child to make up for the child's problem (Silver, 1989).

In family therapy, parents first need information about their child, including medical, educational, psychological, and psychiatric data. The nature of ADD should be explained. Existing emotional, social, or family problems should be clarified and related to ADD. A treatment plan should be formulated and parents counseled on the necessity of becoming advocates for their son or daughter. Full evaluative information should be shared with the child or adolescent, who must understand the reasons for the difficulties and understand the reasons for the treatment plan (Silver, 1989).

Parents have a critical role to play in helping their child. They need to understand how the problem impacts on fam- 
ily activities. They might think about what the child is good at and the areas in which the child has difficulty. They can then apply this knowledge to planning for many activities that will lead to success in school and academics and making friends and establishing social relationships. Specifically, this could include choosing a camp or selecting sports activities and facilitating outside group activities.

If the child's emotional problems are believed to be secondary to ADD, the focus should be on establishing the necessary educational programs and clarifying the nature of the problem with the individual and the family. If the secondary psychological problems have become so established that they now have a life of their own, however, they must be treated, and psychotherapy may be necessary. Clinicians must understand how ADD interferes with peer and family interactions so it can be explained to the child and become useful in problem solving (Silver, 1989).

\section{CURRENT ISSUES}

Extensive research and new methods of assessment and treatment regarding ADD make it a dynamic and rapidly changing discipline. Some areas of recent study are gender issues, ADD characteristics at different age levels, social deficits, and cross-generational findings.

\section{Gender Issues}

Many more boys than girls are identified as having ADD. In studies comparing sex ratios, boys outnumber girls, with a range between twice as many to eight times as many boys (Shaywitz \& Shaywitz, 1988). Many of the clinical characteristics found in girls are similar to those described for boys, but some differences are apparent. Girls with ADD have more cognitive and language deficits and greater social liability. Boys with ADD show more physical aggression and loss of control (Berry, Shaywitz, \& Shaywitz, 1985; Shaywitz, 1987).

The reasons for these gender differences remain speculative. ADD may have biological roots, with males being more vulnerable to ADD. Or ADD may entail cultural bias, with more referral of boys than girls because boys tend to show more disruptive behaviors that are troublesome to adults. Also, boys may be under more pressure than girls to succeed at school, making them more vulnerable to effects of stress. Some researchers suspect that girls with ADD are an underidentified and underserved group at significant risk for long-term academic, social, and emotional difficulties (Shaywitz \& Shaywitz, 1988).

\section{Developmental Characteristics of ADD}

ADD has different manifestations as the child matures, and the symptoms show a developmental trend. The disorder appears at an early age and often persists into later life. Many children with ADD do not outgrow the problem, but the characteristics change at different stages of life. Until age 3, activity level increases, but then it slows down. By adolescence, gross motor hyperactivity is no longer present, although attentional deficits persist. Certain symptoms, such as hyperactivity, may diminish, but others, such as academic difficulties, behavioral problems, poor peer acceptance, low self-esteem, and at times, depression, are evident. Secondary problems often become more prominent. Although many of the symptoms persist, previously hyperactive young adults fare better in the workplace than they did in the classroom (Shaywitz, 1987; Teeter, 1991; Weiss \& Hechtman, 1986).

Some of the developmental characteristics of ADD at different stages are (Campbell, 1990; Teeter, 1991):

Infancy: excessive crying, undue sensitivity, difficult to soothe.

- Toddler: stressful mother-child interaction; less compliant.

- Preschool: excessive activity; noncompliant, difficult to toilet train; shifts activities in free play; high activity levels during structured activities, impulsive responding, negative encounters with others.

- Elementary ages: poor school performance, failure to finish assignments; disruptive in class, poor social relations, aggressive, possible opposition behavior, low attention, easily frustrated.

- Adolescence: problems with following rules and assuming responsibilities, more conduct problems, social problems, antisocial behavior, self-control problems, academic failure.

ㄱ Adult: social problems, depression, low self-esteem.

These changes in symptoms during different age levels suggest different treatment needs. During infancy and toddler stages, treatment should focus on building positive parent-child relationships. During the preschool stage, parent training should emphasize consistent and firm limit setting, with reasonable and fair expectations. Social skills training for preschool children may also be necessary so the child can learn to share and take turns and not to grab toys or hit 
others. During the elementary years, ADD children may need extra instructional opportunities and behavior management to counter their disruptive behavior in the classroom. In the adolescent stage, interventions should be directed toward improved academic competencies, how to handle social situations and pressures, conflict resolution, and selfcontrol cognitive and behavioral strategies (Teeter, 1991).

\section{Social Deficits}

Many children with ADD have serious interpersonal difficulties and experience peer rejection. Although not all children with ADD have social skills deficits, it is a problem for many. Children with ADD with hyperactivity (ADDH) as well as those with ADD without hyperactivity $(\mathrm{ADD} / \mathrm{noH})$ score lower than their peers on popularity ratings, but the ADDH children rate lower in popularity and peers actively dislike them. Hyperactive children are likely to be intrusive, boisterous, annoying, and generally aversive to peers and others; children with $\mathrm{ADD} / \mathrm{noH}$ tend to be more socially withdrawn (Lahey \& Carlson, 1991; Landau \& Moore, 1991; Shaywitz \& Shaywitz, 1988).

Attention to social problems is important because peer relations are predictive of most accepted outcome measures of adolescent and adult mental health as employed in clinical research. Social rejection may lead to secondary symptoms including poor self-esteem, depression, and antisocial behaviors. Moreover, early disturbed peer relations predict premature dropping out of school, juvenile delinquency, job termination, bad conduct discharges from the military, police contacts, and psychiatric hospitalizations. Early peer problems not only indicate concurrent difficulties for the child but also represent a significant at-risk marker for later emotional and behavioral disturbance (Landau \& Moore, 1991; Parker \& Asher, 1987; Shaywitz \& Shaywitz, 1988).

Treatment for social skills deficits includes psychopharmalogical treatment, behavioral interventions, cognitive-behavioral interventions, and combination therapies (Landau \& Moore, 1991). Psychopharmalogical treatment with stimulant medication, usually Ritalin, has been found to be effective in reducing hyperactivity. And less hyperactivity enhances the child's social acceptance (Whalen \& Henker, 1991).

Behavioral interventions to improve the social functioning of children with ADD employ an array of behavior modification and reinforcement methods. Cognitive-behavior interventions focus on teaching cognitive and self-instructional strategies for negotiating interpersonal exchanges. Because this is a relatively new approach to improving social competencies, research is needed to substantiate its efficacy.

Finally, combining several therapies concurrently may reinforce the efficacy of treatment. Although few studies have examined the combined effects of several therapies on social functioning, the combination approach looks promising (Landau \& Moore, 1991).

\section{Cross-Generational Findings}

Evidence from a number of investigations points to a strong genetic influence in ADD. Family studies, twin studies, foster child rearing studies, and neurochemical studies suggest that the child is born that way. Others in the family-fathers, uncles, siblings - often report having had similar problems (Shaywitz, 1987; Shaywitz \& Shaywitz, 1988). The genetic/biological factors may be related to abnormalities in neurological function, in particular to disturbances in brain neurochemistry involving a class of brain neurochemicals called neurotransmitters.

\section{SUMMARY}

Because so many children are being diagnosed with attention deficit disorders (ADD), educators should become familiar with the condition. Special education legislation, specifically the Individuals with Disabilities Education Act (IDEA) and Section 504 of the Rehabilitation Act recognize ADD. Children can be served under learning disabilities, serious emotional disturbances, or other health impaired.

The literature reveals several historical phases in the thinking about this disorder, reflected in the terms brain damage syndrome, minimal brain dysfunction (MBD), hyperkinetic reaction of childhood, attention deficit disorders: $\mathrm{ADDH}$ and $\mathrm{ADD} / \mathrm{noH}$, and attention-deficit hyperactivity disorder (ADHD).

Methods of school assessment include teacher rating scales, direct observation, peer ratings and sociometrics, and measures of academic performance. Treatment may consist of medical, educational, family counseling, and parent training methods. Most experts believe that a combination of methods is the most effective approach.

Current issues affecting ADD include gender differences, developmental characteristics of ADD, social deficits, and cross-generational research. ADD remains a complex and puzzling condition for many children in the schools, and much research remains to be accomplished on all fronts. 


\section{REFERENCES}

Abikoff, H. (1991). Cognitive training in ADHD children: Less to it than meets the eye. Journal of Learning Disabilities, 24, 205-209.

Abikoff, H., Gittelman, R., \& Klein, D. (1980). Classroom observation code for hyperactive children: A replication of validity. Journal of Consulting \& Clinical Psychology, 48, 772-783.

Abramowitz, A. J., \& O'Leary, S. G. (1991). Behavior interventions for the classroom: Implications for students with ADHD. School Psychology Review, 20, 221-235.

American Psychiatric Association (1968). Diagnostic and statistical manual of mental disorders (2nd ed.) (DSM II). Washington, DC: APA.

American Psychiatric Association (1980). Diagnostic and statistical manual of mental disorders (3rd ed.) (DSM III). Washington, DC: APA.

American Psychiatric Association (1987). Diagnostic and statistical manual of mental disorders (3rd ed., rev.) (DSM III-R). Washington, DC: APA.

American Psychiatric Association (in process). Diagnostic and statistical manual of mental disorders (4th ed.) (DSM IV). Washington, DC: APA.

Anastopoulos, A., DuPaul, G., \& Barkley, R. (1991). Stimulant medication and parent training therapies for attention deficit-hyperactivity disorder. Journal of Learning Disabilities, 24, 210-218.

Atkins, M. S., \& Milich, R. (1988). The IOWA-Conners Teacher Rating Scale. In M. Hersen \& A. Bellack (Eds.), Dictionary of behavioral assessment techniques (pp. 273-274). New York: Pergamon Press.

Atkins, M. S., \& Pelham, W. E. (1991). School-based assessment of attention deficit-hyperactivity disorder. Journal of Learning Disabilities, 24, 197-204.

August, G. L., \& Garfinkel, B. D. (1989). Behavioral and cognitive subtypes of ADHD. Journal of the American Academic of Child \& Adolescent Psychiatry, 28, 739-748.

Barkley, R. A. (1977). A review of stimulant drug research with hyperactive children. Journal of Child Psychology and Psychiatry, 18, 137-165.

Barkley, R. A. (1990). Attention deficit hyperactivity disorders: A handbook for diagnosis and treatment. New York: Guilford Press.

Barkley, R. A., DuPaul, G. J., \& McMurray, M. B. (1991). Attention deficit disorder with and without hyperactivity: Clinical response to three dose levels of methylphenidate. Pediatrics, 87(4), 519-531.

Berry, C. A., Shaywitz, S. E., \& Shaywitz, B. A. (1985). Girls with attention deficit disorder: A silent minority? A report on the behavioral and cognitive characteristics. Pediatrics, 76, 807-809.

Bursuck, W. D., Rose, E., Cowen, S., \& Yahaya, M. (1989). Nationwide survey of postsecondary education services for students with learning disabilities. Exceptional Children, 56, 236-254.

Campbell, S. B. (1990). The socialization and social development of hyperactive children. In M. Lewis \& S. Miller (Eds.), Handbook of developmental psychopathology (pp. 77-92), New York: Plenum Press.

Cantwell, D. P., \& Baker, L. (1991). Association between attention deficithyperactivity disorder and learning disorders. Journal of Learning Disabilities, 24, 88-95.

Cherkes-Julkowski, M., \& Stolzengerg, J. (1991). The learning disability of attention deficit disorder. Learning Disabilities: A Multidisciplinary Journal, 2(1), 8-15.

Cherkes-Julkowski, M., Stolzengerg, J., \& Segal, L. (1991). Prompted cognitive testing as a diagnostic compensation for attentional deficits: The Raven Standard Progressive Matrices and attention deficit disorder. Learning Disabilities: A Multidisciplinary Journal, 2(1), 1-7.
Clements, P. (1966). Minimal brain dysfunction in children (NINDS Monograph No. 3, Public Health Bulletin No. 1415). Washgton, DC: U.S. Department of Health, Education, and Welfare.

Clements, S. D., \& Peters, J. E. (1962). Minimal brain dysfunciton in the school-aged child. Archives of General Psychiatry, 6, 185-187.

Clements, S. D., \& Peters, J. E. (1966). Minimal brain dysfunction in children: Terminology and identification (Public Health Service Publication No. 1415). Washington, DC: U.S. Department of Health, Education, and Welfare.

Conners, C. K. (1969). A teacher rating scale for use in drug studies with children. American Journal of Psychiatry, 126, 884-888.

Conners, C. K. (1973). Rating scales for use in drug studies with children (special issue). Psychopharmacology Bulletin, pp. 24-84.

Council for Exceptional Children (1991). CEC Response to Notice of Inquiry: Children with ADD. CEC News. April 17.

Council for Learning Disabilities: CLD (1991). Letter to Office of Special Education Programs in response to Notice of Inquiry: Attention Deficit Disorder, March 26.

Deshler, D. D., \& Schumaker, J. B. (1986). Learning strategies: An instructional alternative for low-achieving adolescents. Exceptional Children, 52, 583-590.

DuPaul, G. J., Barkley, R. A., \& McMurray, M. B. (1991). Therapeutic effects of medication on ADHD: Implications for school psychologists. School Psychology Review, 20, 203-219.

(1990, Dec.). ED issues/questions on attention deficit disorder. Education of the Handicapped, 16(25), 1-2.

(1991, Sept.). ED clarifies stance on ADD, Says students must be served. Education of the Handicapped, 17, 1,3.

Ellis, E. S., Deshler, D. D., Lenz, B. K., Clark, F. L., \& Schumaker, J. B. (1991). An instructional model for teaching learning strategies. Focus on Exceptional Children, 23(6), p. 11.

Epstein, M. A., Shaywitz, S. E., Shaywitz, B. A., \& Woolston, J. L. (1991). The boundaries of attention deficit disorder. Journal of Learning Disabilities, 24, 78-86.

(1991). On the Public Policy Front. Exceptional Children, 23(3), 62.

Fletcher, J., Morris, R., \& Francis, D. (1991). Methodological issues in the classification of attention-related disorders. Journal of Learning Disabilities, 24, 72-79.

Frick, P. J., \& Lahey, B. B. (1991). Nature and characteristics of attentiondeficit hyperactivity disorder. School Psychology Review, 20, 163-173.

Gittelman-Klein, R., \& Klein, D. G. (1987). Pharmacotherapy of childhood hyperactivity: An update. In H. Y. Meltzer (Ed.), Psychopharmacology-The third generation of progress (pp. 1215-1224). New York: Raven Press.

Goldstein, K. (1936). Modification of behavior subsequent to cerebral lesion. Psychiatric Quarterly, 10, 539-610.

Goldstein, S., \& Goldstein, M. (1990). Managing attention disorders in children: A guide for practitioners. New York: Wiley Interscience Press.

Harris, K. R., \& Pressley, M. (1991). The nature of cognitive strategy instruction: Interactive strategy construction. Exceptional Children, 57, 391-404.

Henker, B., \& Whalen, C. K. (1989). Hyperactivity and attention deficits. American Psychologist, 44, 215-223.

Kelly, P. C., Cohen, M. L., Walker, W. O., Caskey, O. L., \& Atkinson, A. W. (1991). Self-esteem in children medically managed for attention deficit disorder. Pediatrics, 83, 211-217.

Kendall, P. C., \& Braswell, L. (1985). Cognitive behavioral therapy for impulsive children. New York: Guilford. 
Kirk, S., \& Gallagher, J. (1989). Educating exceptional children. Boston: Houghton Mifflin.

Lahey, B. B., \& Carlson, C. L. (1991). Validity of the diagnostic category of attention deficit disorder without hyperacitivity: A review of the literature. Journal of Learning Disabilities, 24, 110-120.

Landau, S., \& Moore, L. A. (1991). Social skill deficits in children with attention-deficit hyperactivity disorder. School Psychology Review, 20, 235-251.

Laufer, M., \& Denhoff, E. (1957). Hyperkinetic behavior syndrome in children. Journal of Pediatrics, 50, 463-474.

Learning Disabilities Association (1991). LDA Legislative Update, May 28.

Learning Disabilities Association (1991). Response to notice of inquiry regarding attention deficit disorder. LDA Newsbriefs, 16(3), 1, 5-7.

Loney, J., \& Milich, R. (1982). Hyperactivity, inattention, and aggression in clinical practice. In M. Wolraich \& D. K. Routh (Eds.), Advances in behavioral pediatrics (Vol: 2, pp. 113-137). Greenwich, CT: JAI Press.

Madsen, C. (1990). ADD/ADHD recognized as handicapping conditions under Section 504, Rehabilitation Act of 1973. HAAD Enough, Jan./Feb., 10-11.

McBurnett, K., \& Pfiffner, L. J. (1991). ADHD and LD. Journal of Learning Disabilities, 24, 258-259.

Meichenbaum, D. (1977). Cognitive-behavior modification: An integrative approach. New York: Plenum Press.

Meichenbaum, D., \& Goodman, J. (1971). Training impulsive children to talk to themselves: A means of developing self control. Journal of Abnormal Psychology, 77, 115-126.

Meyer, A. (1904). The anatomical facts and clinical varieties of traumatic insanity. American Joumal of Insanity, 60, 373-441.

Newby, R. F., \& Fischer, M. (1991). Parent training for families of children with ADHD. School Psychology Review, 20, 252-265.

OSEP sends notice of inquiry summary on ADD to Congress. (1991). Special Educator, 6(18), 255, 257.

Parker, H. C. (1988). The ADD hyperactivity workbook for parents, teachers, and kids. Plantation, FL: Impact Publications.

Parker, H. C. (1990). CH.A.D.D. Education position paper. CH.A.D.D.: Children with Attention Deficit Disorders, 4(1), 19-28.

Parker, J. G., \& Asher, S. R. (1987). Peer relations and later personal adjustment: Are low-accepted children at risk? Psychological Bulletin, 102, 357-389.

Pelham, W. E., \& Milich, R. (1984). Peer relations in children with hyperactivity/attention deficit disorder. Journal of Learning Disabilities, $17,560-567$.

Pfiffner, L. J., \& Barkley, R. A. (1990). Classroom management methods. In R. A. Barkley (Ed.), Attention deficit hyperactivity disorders: A handbook for diagnosis and treatment (pp. 438-539). New York: Guilford Press.

Pliszke, S. R. (1987). Tricyclic antidepressants in the treatment of children with attention deficit disorder. Journal of the American Academy of Child \& Adolescent Psychiatry, 26, 127-132.

Reeves, R. (1990, Sept./Oct.). Serving children with ADHD in the schools. HAAD Enough, pp. 3-4.

Schaughency, E. A., \& Rothlind, J. (1991). Assessment and classification of attention-deficit hyperactivity disorders. School Psychology Review, 20, 187-202.
Shaywitz, B. (1987). Hyperactivity/attention deficit disorder. Leaming disabilities: A report to U.S. Congress. Washington, DC: Interagency Committee on Learning Disabilities.

Shaywitz, S., \& Shaywitz, B. (1988). Attention deficit disorder: Current perspectives. In J. Kavanagh \& J. Truss (Eds.), Learning disabilities: Proceedings of the national conference (pp. 369-567). Parkton, MD: York Press.

Shaywitz, S., \& Shaywitz, B. (1991). Introduction to the special series on attention deficit disorder. Journal of Learning Disabilities, 24, 68-71.

Silver, L. B. (1989). Psychological and family problems associated with learning disabilities: Assessment and intervention. Journal of the American Academy of Child \& Adolescent Psychiatry, 28, 319-325.

Silver, L. B. (1990). Attention deficit-hyperactivity disorder: Is it a learning disability or a related disorder? Journal of Learning Disabilities, 23, 394-397.

Silver, A., \& Hagin, R. (1990). Disorders of learning in childhood. New York: Wiley.

Still, G. E. (1902). The Coulstonian Lectures on some abnormal physical conditions in children. Lancet, 1:10018-12, 1007-82, 1163-68.

Strauss, A. A., \& Lehtinen, L. E. (1947). Psychopathology and education of the brain-injured child. New York: Grune \& Stratton.

Swanson, J. M., Cantwell, D., Lerner, M., McBurnett, K., \& Hanna, G. (1991). Effects of stimulant medication on learning in children with ADHD. Journal of Learning Disabilities, 24, 219-230.

Teeter, P. A. (1991). Attention-deficit hyperactivity disorder: A psychoeducational paradigm. School Psychology Review, 20, 266-280.

Thomas, S. F. (1990). Washington highlights. CH.A.D.D.ER, 4(2), 7.

Torgesen, J. K., Kistner, J. A., \& Morgan, S. (1987). Component processes in working memory. In J. G. Borkowski \& J. D. Days (Eds.), Cognition in special children: Comparative approaches to retardation, learning disability, and giftedness (pp. 49-86). Norwood, NJ: Ablex.

U.S. Department of Education (1991). To assure the free appropriate public education of all children with disabilities (Thirteenth Annual Report to Congress on the Implementation of the Education of the Handicapped Act). Washington, DC: U.S. Government Printing Press.

Vogel, S. A. (1987). Issues and concerns in LD college programming. In D. J. Johnson \& J. W. Blalock (Eds.), Adults with learning disabilities. Orlando, FL: Grune \& Stratton.

Weiss, G., \& Hechtman, L. T. (1986). Hyperactive children grown up: Empirical findings and theoretical considerations. New York: Guilford.

Werner, H., \& Strauss, A. (1940). Causal factors in low performance. American Journal of Mental Deficiency, 45, 213-218.

Werner, H., \& Strauss, A. S. (1941). Pathology of the figure-background relation in the child. Journal of Abnormal \& Social Psychology, 36, 234-248.

Werry, J., Sprague, R., \& Cohen, M. (1975). Conners Teaching Rating Scale for use in drug studies with children: An empirical study. Journal of Abnormal Child Psychology, 3, 217-229.

Whalen, C., \& Henker, B. (1991). Social impact of stimulant treatment for hyperactive children. Journal of Learning Disabilities, 24, 231-241. 


\section{Professional update}

\section{SPECIAL EDUCATION RESOURCES}

Curriculum Considerations in Inclusive Classrooms: Facilitating Learning for All Students by Susan Stainback and William Stainback, Foreword by Jack Pearpoint and Marsha Forest. Published by Paul H Brookes Publishing Company, Baltimore, Maryland, 1992.

This follow-up book to Support Networks for Inclusive Schools and Educating All Students in the Mainstream of Regular Education promises to show you how to integrate all students into a regular classroom.

Topics covered include the process by which educators and administrators work together to develop, implement, and evaluate a school curriculum that makes inclusion classrooms possible. The authors suggest ways, including student collaboration, to gain active participation of everyone involved in an inclusive classroom.
Go For It! A Book on Sport and Recreation for Persons with Disabilities edited by Jerry D. Kelley and Lex Frieden. Published by Harcourt Brace Jovanovich, Orlando, Florida, 1989.

Originally inspired by Queen Silvia of Sweden, Go For It! was conceived and developed as a cooperative project of the Swedish Royal Wedding Trust, the International Alliance on Disability, and Harcourt Brace Jovanovich. It was the recipient of the 1989 National Literary Award given by the National Recreation and Park Association.

Go For It! provides information on the numerous athletic activities available for those with disabilities, including team and individual sports, aquatics, track and field, winter sports, dance, and fitness. This "how and why" guidebook is filled with color pictures and offers everything from the tame to the daring (mountain climbing in a wheelchair!).

\section{PERMISSIONS AND COPYRIGHT}

All rights are reserved. No part of this publication may be reproduced, photocopied, faxed, stored in a retrieval system, or transmitted, in any form or by any means, electronic, mechanical, recording or otherwise, without the prior written permission of the publisher.
Back issues are available for sale. Reproduction requires permission and payment of fees. It is illegal and a violation of Federal copyright law to reproduce this publication without permission. Direct all inquiries to the permissions editor. 


\section{SPECIAL EDUCATION RESOURCES}

(continued)

\section{ERIC Clearinghouse on Handicapped and Gifted Children, The Council for Exceptional Children, Reston, Virginia.}

The ERIC Clearinghouse has several new volumes available.

Integrating Services for Children and Youth with Emotional and Behavioral Disorders by C. Michael Nelson and Cheryll A. Pearson.

In this monograph, the authors cover topics such as:

- why interagency programs and services are needed

- the benefits of collaborative programs

- characteristics of children and youth with EBD

- the legislation, litigation, funding mechanisms, and advocacy issues affecting interagency coordination

- the roles of the disciplines involved in interagency programs

- the models used by professionals in mental health and education, and several existing models of interagency service delivery

\section{Exceptional Children at Risk-CEC Mini-Library}

The 11 booklets in this series include:

口 Programming for Aggressive and Violent Students

- Abuse and Neglect of Exceptional Children

- Special Health Care in the School

- Homeless and in Need of Special Education

- Hidden Youth: Dropouts from Special Education

․ Born Substance Exposed, Educationally Vulnerable

ㅁ Depression and Suicide: Special Education Students at Risk

- Language-Minority Students with Disabilities

ㅁ Alcohol and Other Drugs: Use, Abuse and Disabilities

口 Rural, Exceptional, at Risk

ㅁ Double Jeopardy: Pregnant and Parenting Youth in Special Education
CEC Mini-Library:

Working with Behavioral Disorders edited by Lyndal M.

Bullock and Robert B. Rutherford.

The nine volumes in this mini-library are:

- Teaching Students with Behavioral Disorders: Basic Questions and Answers

$\checkmark$ Conduct Disorders and Social Maladjustments: Policies, Politics, and Programming

- Behaviorally Disordered? Assessment for Identification and Instruction

- Preparing to Integrate Students with Behavioral Disorders

- Teaching Young Children with Behavioral Disorders

a Reducing Undesirable Behaviors

- Social Skills for Students with Autism

- Special Education in Juvenile Correction

- Moving On: Transitions for Youth with Behavioral Disorders 


\section{Behind Special Education}

\section{A Critical analysis of Professional Culture and School Organization}

Thomas M. Skrtic

University of Kansas

This new work is a critical analysis of the nature of disability, special education, school organization, and reform progress. It compares values to actual outcomes. It asks if what we do is what we really believe is best for the children, families and society. The book develops a conceptual framework to analyze PL 94-142, the regular education initiative, and the excellence movement. The volume proposes a new alternative configuration for school organization. All forward thinking educators will want this new book on their desk. The author makes a new proposal that allows the excellence goals of general education and the equity goals of special education to be addressed at the same time. This innovative text brings new perspectives to the field of special education and regular education for policy and leadership.

9-9007/paper/ISBN 0-89108-217-4

$\$ 24.95$

\section{Contents}

Part One - PROBLEMS AND PROSPECTS

1. The Crisis in Modern Knowledge

2. Critical Pragmatism as a Method of Social Inquiry

Part Two - PROFESSIONAL CULTURE

3. The Crisis in Special Education

4. The Crisis in the Professions

5. The Special Education Knowledge Tradition

6. Critical Pragmatism as a Mode of Professional Discourse

Part Three - SCHOOL ORGANIZATION

7. Two Discourses on School Organization

8. Toward an Antifoundational Theory of School Organization

9. Special Education and Disability as Organizational Pathologies

10. Special Education Paradox 